\title{
Effect of tyramine in migraine: a double-blind study
}

\author{
ADRIENNE MOFFETT, MICHAEL SWASH, AND D. F. SCOTT \\ From the Departments of Neurology and EEG, Section of Neurological Sciences, \\ The London Hospital, London
}

SUMMARY The incidence of headache and changes in the EEG after tyramine were studied in 250 migrainous patients in a double-blind placebo-controlled investigation. There were three groups of $\frac{\overline{\bar{N}}}{\overline{0}}$ patients: the first had migraine alone, the second had migraine and epilepsy, and the third had $\frac{\sigma^{2}}{\vec{\sigma}}$ migraine which was precipitated by food substances containing tyramine. Psychological tests showed $\varrho$ that all the patients were more neurotic, more introverted, and more obsessional than normalis subjects. Headache occurred in 12 of 50 patient sessions and 10 of these occurred in the group with $\overrightarrow{0}$ dietary precipitated migraine. In this group, however, headache followed tyramine alone in only $\overrightarrow{\vec{\omega}}$ two patients. The remaining eight headaches occurred in two patients after placebo alone, and in $)$ three after both test capsules. The EEG was activated after tyramine, but not after placebo, in 11 of the 15 patients with migraine and epilepsy, and dietary precipitated migraine. This effect was ob-o served, however, in only two of the 10 patients with classical migraine alone. There was no relation between the occurrence of headache and EEG activation. Although there was no significant relation. ship between tyramine ingestion and the occurrence of headache, the EEG changes observed durin the study support the hypothesis that tyramine has an action on the central nervous system in songe응 migrainous subjects.

About $5 \%$ of migrainous subjects notice that certain foods, known to contain large amounts of free tyramine, may induce typical migraine headache. Indeed, Hanington $(1967,1969)$, and Hanington, Horn, and Wilkinson (1970) have shown that about $70 \%$ of these subjects develop typical migraine headache three to 18 hours after the ingestion of $125 \mathrm{mg}$ tyramine. Youdim, Carter, Sandler, Hanington, and Wilkinson (1971) have suggested that the headacheinducing effect of tyramine may be due to defective conjugation of ingested tyramine in the intestinal wall of susceptible individuals. Further, dietary tyramine is known to induce hypertension and headache in non-migrainous patients taking monoamine oxidase inhibitor drugs (Blackwell and Mabbitt, 1965) and this effect has been shown to be due to inhibition, by these drugs, of intestinal and hepatic breakdown of dietary tyramine so that large amounts of tyramine, which is a pressor substance, accumulate (Blackwell and Marley, 1964; Tedeschi and Fellows, 1964). However, none of Hanington's patients was hypertensive at the time of their tyramine-induced headaches and none was taking monoamine oxidase inhibitor drugs (Hanington,
1967, 1969). The mechanism of action of tyres mine in migraine is uncertain and Blau $(197 \Phi) \vec{\omega}$ has pointed out that, if this were a pharmä- $N$ cological effect, the variable delay between ingestion of tyramine and the occurrence of headache would be most unusual.

The electroencephalograms (EEGs) of mi-气 grainous subjects may be markedly abnormal $\stackrel{\mathbb{Q}}{\complement}$ during an attack (Slatter, 1968) but it is a well $\overrightarrow{0}$ established, and yet a poorly understood 3 observation, that the resting EEGs of migrainous subjects are also frequently abnormal, containing poorly organized background activity and $\overline{\bar{F}}$ excessive amounts of both generalized and? localized theta activity (Slatter, 1968). These 3 changes are similar to those found in the inter-i ictal recordings of epileptic patients (Slatter, 3 1968; Basser, 1969) and it seemed a possibilityo that if tyramine induced headache in migrainous subjects it would increase the pre-existing EEG음 abnormality. We have therefore examined the role of tyramine in migraine in more detail ${ }^{\circ}$ using serial EEG recordings as well as clinical and psychological tests. For this purpose oral tyramine was administered in a double blind? placebo controlled study of a group of 25 ? 
selected patients with classical migraine, migraine and epilepsy, and migraine with a history of attacks precipitated by foods containing tyramine. In this paper we report the incidence of headache and its relation to changes in the pre-existing EEG abnormalities after tyramine ingestion.

\section{METHODS}

Twenty-five women with classical migraine, defined according to the criteria of The World Federation of Neurology (Cochrane, 1970) were studied. Their ages ranged from 20 to 57 years; they all usually had two or more attacks of migraine headache in a single month and they were all otherwise healthy. None of the patients was taking oral contraceptive drugs, but several were taking other regular medication, including diazepam, barbiturates, and ergotamine, and they were allowed to continue this.

The patients were divided into three groups. Group A consisted of 10 patients with migraine alone (mean age 34 years) and group B consisted of seven patients who had both migraine and epilepsy (mean age 35 years). All these patients had previously attended the neurological clinic at The London Hospital for treatment and none gave a history of a dietary precipitant for their migraine. In group $\mathbf{C}$ there were eight patients (mean age 38 years) who volunteered for the study because they had noticed that certain foods, known to contain tyramine, could precipitate their headache. The trial was doubleblind and placebo controlled and it was fully balanced in groups A and C. In group B, however, an eighth patient with both migraine and epilepsy could not be obtained.

At the initial visit each patient had a full clinical examination to exclude other disease and an EEG recording, and a series of psychological tests was administered. These included a mood scale (Reynolds, Joyce, Swift, Tooley, and Weatherall, 1965), the Eysenck Personality Inventory (Eysenck and Eysenck, 1964), the Leyton Obsessional Inventory (Cooper, 1970), and Raven's Matrices (Raven, 1938). As far as possible these tests were administered at the initial attendance but it was not usually possible to complete them then and the remainder were administered during one of the other visits.

Each patient attended on two subsequent occasions four to seven days apart, and on the evening before each of these visits a mood scale test was completed at home. On awakening on the morning of an attendance each patient took a capsule, which on one occasion contained $125 \mathrm{mg}$ tyramine, and on the other $125 \mathrm{mg}$ lactose placebo, and then, after breakfast, attended the EEG department where a mood scale test was administered and an EEG was recorded. The occurrence of headache was assessed by interview at each of these visits, which took place four to seven hours after capsule ingestion, and again, by questionnaire, 48 hours later. The blood pressure was measured at each visit. All the patients completed this schedule satisfactorily.

When the study had been finished the EEGs were coded and masked and then rated independently by M.S. and D.F.S. according to criteria established by these observers in a previous investigation (Swash, Rowan, and Scott, 1971; Swash and Rowan, 1972). The preliminary EEGs, which were taken to familiarize the patients with the procedure, were discarded from this analysis.

\section{RESULTS}

Headache occurred after ingestion of a capsule in 12 of 50 patient sessions. One headache followed placebo in group $A$ and one followed tyramine in group B. The remaining 10 headaches occurred in group C. In this group two headaches occurred after tyramine, two after placebo and six, in three patients, after both test capsules. None of the headaches reported during the study was typical of these patients' usual migraine headaches. One spontaneous migraine headache occurred during the study, but this did not interfere with the test schedule. Unfortunately, it was not possible to record an EEG during this attack.

The EEG abnormalities observed in the 50 records studied consisted, in summary, of episodic lateralized frontotemporal theta activity and episodic bilateral theta and delta wave forms at rest. These changes were accentuated by hyperventilation. Frank paroxysmal activity was seen only in the EEGs of epileptic subjects (group B). More severe abnormalities were observed in the EEG records made after tyramine ingestion in five of the seven patients in group B, and in six of the eight patients in group $\mathrm{C}$, but in only two of the 10 patients. in group $A$ (Table). These findings in groups $\mathbf{B}$ and $\mathbf{C}$ are significantly different from those in group A $(P=0.05<>0.02)$. In addition, the specifically epileptic features present in the EEGs of the patients in group B were also activated after

TABLE

\begin{tabular}{lrrcccc}
\hline & & \multicolumn{3}{c}{ Headache after } & \multirow{2}{*}{$\begin{array}{c}\text { EEG activated } \\
\text { by tyramine }\end{array}$} \\
\cline { 3 - 5 } & $n$ & Tyramine & Placebo & Both & \\
\hline Group A & 10 & - & 1 & - & 2 \\
Group B & 7 & 1 & $\frac{1}{3}$ & $-5^{*}$ \\
Group C & 8 & 2 & 2 & $6^{*}$ \\
\hline
\end{tabular}

* $P=0.05<>0.02$ 
tyramine. All these EEG changes occurred independently of headache and in no instance were EEG abnormalities more marked in those records made after ingestion of lactose placebo than in those made after tyramine ingestion. The EEG abnormalities found in the three groups of patients and details of the nature of the EEG activation observed will be fully described in a subsequent paper (Scott, Moffett, and Swash, 1972).

The psychological tests showed an excess of neuroticism, introversion, and obsessionality in all three groups of patients. These features were most pronounced in groups $\mathrm{B}$ and $\mathrm{C}$. In addition the patients in group $C$ had a slightly higher intelligence score than the others. There was no relationship between changes in mood and tyramine ingestion, the occurrence of headache, or EEG activation. No change in blood pressure was noted after tyramine ingestion.

\section{DISCUSSION}

In their studies of the role of tyramine in migraine Hanington, $(1967,1969)$ and Hanington et al. (1970) found that $70 \%$ of a group of 36 susceptible subjects developed headache after oral tyramine. Although our patients were given the same dose of this substance, only two of the eight patients in group $\mathrm{C}$, who were selected by the same criteria as those used by Hanington, suffered headache after oral tyramine. In addition, two patients in this group reported headache after placebo and three after both tyramine and placebo. Only two of the 12 headaches observed during the whole study occurred in groups A and B and none of these headaches was typical of these patients' usual migraine. The patients in group $\mathrm{C}$ differed from those in the other groups. They were all volunteers, self selected by having noticed a tendency for their migraine attacks to be precipitated by dietary factors, and they therefore expected to develop headache after one or both test capsules. In addition, they achieved higher scores in tests of introversion, neuroticism, obsessionality, and intelligence than patients in groups A and B. It is suggested that the high incidence of headache in this group may have been due to the interaction of these various factors rather than to any pharmacological action of lactose or tyramine.

There are a number of other possible explanations for the discrepancy between our results and those of Hanington. One factor might be that the frequent occurrence of placebo head- $z$ aches was due to the stress of hospital attendances required during the study. That this is an unlikely cause is shown by the absence of headache during the first, and, presumably, most stressful visit and the absence of change in the mood scale scores during the study. Another explanation might be that our subjects failed to $\stackrel{0}{\overrightarrow{7}}$ take their tyramine-containing test capsule. However, the demonstration of significant EEG $\vec{\Rightarrow}$ activation after tyramine in 13 of our 25 patients, $\overrightarrow{0}$ of whom 11 were in groups $B$ and $C$, which믈 together consisted of 15 patients, is strong $\frac{\overline{\bar{p}}}{\vec{D}}$ evidence against this. Furthermore, the activating $\stackrel{\mathbb{Q}}{\Omega}$ effect of tyramine on the EEG was not striking in the patients in group $A$ who had migraine $\vec{\circ}$ alone. EEG activation occurred after tyramine in only two of the 10 patients in this group.

Although we have not observed a significant $\stackrel{\circ}{-}$ number of headaches after tyramine in any of the three groups of migrainous patients studied, the finding of EEG activation after tyramine $\rightarrow$ ingestion suggests that tyramine, one of i $\overrightarrow{0}$ metabolites, or a substance released by tyramira can cross the blood brain barrier. This effect w striking in the patients with migraine and epi lepsy, and dietary-induced migraine who formedc groups $\mathrm{B}$ and $\mathrm{C}$, and in both these groups $\frac{\text { Qt }}{2}$ occurred with a frequency comparable with the of headache in Hanington's patients. There evidence, therefore, that these patients reacted differently to oral tyramine than did those with classical migraine alone. However, the failure of our patients to develop migraine headache after tyramine remains contrary to Hanington's $\frac{2}{\square}$ experience. Since the response to tyramine has $\overrightarrow{\vec{P}}$ not yet been shown to be a pharmacological one $\frac{3}{3}$ (Blau, 1971) it would be worth attempting to confirm Hanington's observations by studying the effect of tyramine at different dosages, using a similar double-blind trial design.

Finally, it should be noted that this study demonstrates, firstly, the importance of a careful double-blind trial design in studies of $\varrho$ the effects of pharmacological or therapeutic substances in patients with migraine; secondly, 은 the importance of personality factors in the $\frac{7}{0}$ production of subjective symptoms such as headaches; and, thirdly, the value of serial EEG $\mathcal{N}$ recordings in pharmacological studies of pre- $N$ cipitating factors in migraine.

This work was supported by the Wellcome Trust 
who provided a salary for A.M. and incidental expenses. During the study M.S. was in receipt of an M.R.C. grant. We wish to thank Dr. R. A. Henson and Dr. C. J. Earl who allowed us to study their patients and we are especially grateful to Dr. Edda Hanington who referred the patients in group C. We are indebted to the technicians of the EEG department who carried out the recordings and finally to our patients who volunteered to take part in the study. A preliminary report of this work was read at a joint meeting of the Royal Society of Medicine and the Deutsche Gesellschaft für Neurologie in Göttingen on 20 June 1971.

\section{REFERENCES}

Basser, L. S. (1969). The relation of migraine and epilepsy. Brain, 92, 285-300.

Blackwell, B., and Mabbitt, L. A. (1965). Tyramine in cheese related to hypertensive crises after monoamineoxidase inhibition. Lancet, 1, 938-940.

Blackwell, B., and Marley, E. (1964). Interaction between cheese and monoamine-oxidase inhibitors in rats and cats. Lancet, 1, 530-531.

Blau, J. N. (1971). Migraine-research. British Medical Journal, 2, 751-754

Cochrane, A. L. (Editor) (1970). Definition of migraine. In Background to Migraine. Third Migraine Symposium, 1969, pp. 181-182. Heinemann: London.

Cooper, J. (1970). The Leyton Obsessional Inventory. Psychological Medicine, 1, 48-64.

Eysenck, H. J., and Eysenck, S. B. G. (1964). Manual of the Eysenck Personality Inventory. University of London Press: London.
Hanington, E. (1967). Preliminary report on tyramine headache. British Medical Journal, 2, 550-551.

Hanington, E. (1969). The effect of tyramine in inducing migrainous headache. In Background to Migraine, Second Migraine Symposium, 1967, pp. 10-18. Edited by R. Smith. Heinemann: London.

Hanington, E., Horn, M., and Wilkinson, M. (1970). Further observations on the effects of tyramine. In Background to Migraine, Third Migraine Symposium, 1969, pp. 113-119. Edited by A. L. Cochrane. Heinemann: London.

Raven, J. C. (1938). Guide to Using the Mill Hill Vocabulary Scale with Progressive Matrices. Lewis: London.

Reynolds, E., Joyce, C. R. B., Swift, J. L., Tooley, P. H., and Weatherall, M. (1965). Psychological and clinical investigation of the treatment of anxious out-patients with three barbiturates and placebo. British Journal of Psychiatry, 111, 84-95.

Scott, D. F., Moffett, A., and Swash, M. (1972). Observations on the relation of migraine and epilepsy on EEG, psychological and clinical study using oral tyramine. Epilepsia. (In press.)

Slatter, K. H. (1968). Some clinical and EEG findings in patients with migraine. Brain, 91, 85-98.

Swash, M., and Rowan, A. J. (1972). EEG criteria of hypocalcaemia and hypercalcaemia. Archives of Neurology. (In press.)

Swash, M., Rowan, A. J., and Scott, D. F. (1971). EEG criteria of hypocalcaemia and hypercalcaemia (abstract). Electroencephalography and Clinical Neurophysiology, 30, 365.

Tedeschi, D. H., and Fellows, E. J. (1964). Monoamine oxidase inhibitors: Augmentation of pressor effects of peroral tyramine. Science, 144, 1225-1226.

Youdim, M. B. H., Carter, S. B., Sandler, M., Hanington, E., and Wilkinson, M. (1971). Configuration defect in tyramine-sensitive migraine. Nature, 230, 127-128. 